\title{
A randomised phase II trial and feasibility study of palliative chemotherapy in frail or elderly patients with advanced gastroesophageal cancer (321GO)
}

P S Hall ${ }^{\star, 1,10}$, S R Lord ${ }^{2,10}$, M Collinson ${ }^{3}, \mathrm{H}$ Marshall ${ }^{3}, \mathrm{M}$ Jones $^{3}, \mathrm{C} \mathrm{Lowe}^{4}, \mathrm{H} \mathrm{Howard}^{3}$, D Swinson ${ }^{5}$,

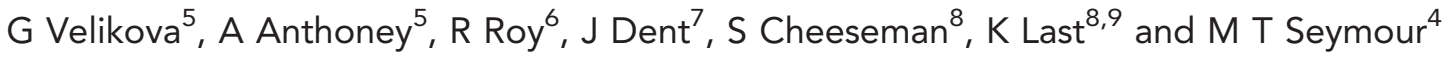

${ }^{1}$ Edinburgh Cancer Research Centre, University of Edinburgh, Edinburgh EH4 2XR, UK; ${ }^{2}$ Department of Oncology, University of Oxford, Oxford, UK; ${ }^{3}$ Leeds Institute of Clinical Trials Research, University of Leeds, Leeds, UK; ${ }^{4}$ NIHR Cancer Research Network Coordinating Centre, Leeds, UK; ${ }^{5}$ Leeds Institute of Cancer and Pathology, University of Leeds, Leeds, UK; ${ }^{6}$ Department of Oncology, Castle Hill Hospital, Hull, UK; ${ }^{7}$ Department of Oncology, Huddersfield Royal Infirmary, Huddersfield, UK; ${ }^{8}$ Department of Oncology, The York Hospital, York, UK and ${ }^{9}$ Department of Oncology, Bradford Royal Infirmary, Bradford, UK

Background: Elderly patients are commonly under-represented in cancer clinical trials. The $321 \mathrm{GO}$ was undertaken in preparation for a definitive phase three trial assessing different chemotherapy regimens in a frail and/or elderly population with advanced gastroesophageal (GO) cancer.

Methods: Patients with advanced GO cancer considered unfit for conventional dose chemotherapy were randomly assigned in a 1:1:1 ratio to: epirubicin, oxaliplatin and capecitabine (EOX); oxaliplatin and capecitabine (OX); and capecitabine alone $(X)$ (all $80 \%$ of full dose and unblinded). The primary end point was patient recruitment over an 18-month period. A registration study recorded treatment choice for all patients with advanced GO cancer at trial centres.

Results: A total of 313 patients were considered for palliative chemotherapy for GO cancer over the 18-month period: 115 received full dose treatment, 89 less than standard treatment or entered $321 \mathrm{GO}$ and 111 no treatment. Within $321 \mathrm{GO}, 55$ patients were randomly assigned (19 to OX and X; 17 to EOX). Progression-free survival (PFS) for all patients was 4.4 months and by arm 5.4 , 5.6 and 3.0 months for EOX, OX and X, respectively. The number of patients with a good overall treatment utility (OTU), a novel patient-centred endpoint, at 12 weeks was 3 (18\%), 6 (32\%) and 1 (6\%) for EOX, OX and X, respectively. At 6 weeks, 22 patients $(41 \%)$ had experienced a non-haematologic toxicity $\geqslant$ grade 3 , most commonly lethargy or diarrhoea. The OTU was prognostic for overall survival in patients alive at week 12 (logrank test $P=0.0001$ ).

Conclusions: It is feasible to recruit elderly and/or frail patients with advanced GO cancer to a randomised clinical trial. The OX is the preferred regimen for further study. Overall treatment utility shows promise as a comparator between treatment regimens for feasibility and randomised trials in the elderly and/or frail GO cancer population.

\footnotetext{
${ }^{*}$ Correspondence: Dr PS Hall; E-mail: p.s.hall@ed.ac.uk

${ }^{10}$ These authors contributed equally to this work
}

Received 18 June 2016; revised 8 November 2016; accepted 5 December 2016; published online 17 January 2017

(c) 2017 Cancer Research UK. All rights reserved 0007-0920/17 
Patients with gastroesophageal (GO) cancer are often frail because of comorbidities and malnourishment. Gastric and oesophageal cancers are largely diseases of the elderly, especially gastric cancer where $77 \%$ of patients are diagnosed over the age of 75 years (Shitara et al, 2009). However, there is a conspicuous mismatch between the age and fitness of patients with advanced GO cancer and that of participants in practice defining randomised controlled trials (RCTs; Trumper et al, 2006, 2006; Cunningham et al, 2008). Response rates to chemotherapy are unaffected by age but comorbid and age-related changes in pharmacokinetics and pharmacodynamics can lead to increased toxicity with doses established in younger patients (Stein et al, 1995; Popescu et al, 1999; Sargent et al, 2001). Hence, an evidence base is needed that addresses treatment choices in the frail and elderly GO cancer population.

In 2008, a regional audit and a national survey in the United Kingdom identified widely varying practice and no standard regimen or dosing strategy in the use of chemotherapy in this patient population. Triple-, double- or single-agent regimens were in use, largely reflecting modifications of standard regimens used at full dose in fitter patients. Three-, two- or one-drug chemotherapy for advanced GO cancer (321GO) is a phase two RCT designed to assess the feasibility of a subsequent phase three RCT that may include diverse chemotherapy treatments in the elderly and/or frail advanced GO cancer population.

\section{MATERIALS AND METHODS}

The $321 \mathrm{GO}$ had several novel design features embedded within it. This included an encompassing registration study that captured all patients presenting to the participating cancer networks with advanced GO cancer, the proportion considered for chemotherapy for advanced GO cancer and the proportion randomised into 321GO. Secondly, a comprehensive assessment of tolerability, quality of life, patient acceptability, patient symptoms and nutrition was undertaken at baseline and weeks 12 and 24 in order to determine (1) whether such an assessment was feasible and (2) best identify which chemotherapy treatment regimens would be used in a phase three trial. Overall treatment utility (OTU), a novel patient-centred composite end point, was also assessed as a tool to discriminate between treatment regimens in this population.

The $321 \mathrm{GO}$ trial took place in six UK centres across two Cancer Research Networks, recruiting patients between June 2009 and January 2011. A key eligibility criterion stated that the patient should not be considered a candidate for standard full-dose three-drug chemotherapy regimens. Patients were required to be considered by the treating clinician to be fit and suitable for reduced-dose chemotherapy. Other eligibility criteria included a requirement for histologically confirmed carcinoma of the oesophagus, gastroesophageal junction or stomach of either squamous, adenocarcinoma or undifferentiated type and planned for treatment with palliative intent. Patients were required to be over the age of 18 years but there was no upper age limit. Patients were excluded if they had previously received chemotherapy for gastric or oesophageal cancer; had another malignancy that in the opinion of the treating consultant would potentially impede interpretation of the outcome of $321 \mathrm{GO}$ therapy; had treatment with another investigational agent within 30 days of commencing treatment; and had previously been treated with anthracyclines to a total cumulative dose of epirubicin of $900 \mathrm{mg} \mathrm{m}^{-2}$ (or equivalent) including the treatment to be administered within this trial. Patients were not excluded for a medical condition unless this impaired their ability to consent or was so severe as to preclude protocol treatment. Minimum organ function required an estimated glomerular filtration rate of $>30 \mathrm{ml} \mathrm{min}^{-1}$, bilirubin less than three times the upper limit of normal (ULN), transaminases less than five times ULN, neutrophils $>1.5 \times 10^{9} / 1$, white cell count $>3 \times 10^{9} / 1$ and platelets $>100 \times 10^{9} / 1$. Current uncontrolled cardiac impairment was also an exclusion criterion.

We obtained written consent after verbal explanation and a written information sheet had been given to the patient, with at least $24 \mathrm{~h}$ allowed for consideration. Thereafter, but before randomisation, a 128-item comprehensive health assessment (CHA) was carried out (Supplementary Appendix). This assessment comprised three nurse-administered modules (including physical parameters, nutrition and medical comorbidity) and five patient-completed modules (including activities of daily living, symptoms, quality of life and medical resource use; Charlson et al, 1987; Nouri and Lincoln, 1987; Aaronson et al, 1993; Kind, 1996; Guigoz and Vellas, 1997; Simonsick et al, 2000; Lagergren et al, 2007).

The $321 \mathrm{GO}$ was approved by the NHS National Research Ethics Service, Sponsored by the University of Leeds and conducted by the University of Leeds Clinical Trials Research Unit and St James Institute of Oncology. The study was registered: ISCTRN33934807.

Study design. Patients were randomly assigned in a $1: 1: 1$ ratio using a central telephone randomisation service. Stratified permuted block randomisation was used with the stratification factors age ( $\leqslant 75$ vs $>75$ years) and the presence of distant metastases (yes $v s$ no). Treatment allocation was not masked. In addition to those patients randomised, a detailed screening log was maintained in order to capture the number of patients in each region with a diagnosis of GO cancer, the proportion of these patients considered fit for full-dose chemotherapy, the proportion randomised into $321 \mathrm{GO}$ or treated with reduced dose nonstandard chemotherapy and those not treated with any chemotherapy.

Procedures. Trial regimens (at $80 \%$ of full dose) were EOX: epirubicin $40 \mathrm{mg} \mathrm{m}^{-2}$ i.v. bolus and oxaliplatin $104 \mathrm{mg} \mathrm{m}^{-2}$ i.v. infusion over $2 \mathrm{~h}$ and capecitabine $500 \mathrm{mg} \mathrm{m}^{-2}$ b.d. on days 1-21, repeated every 21 days. The OX was identical to EOX other than the omission of epirubicin. The $\mathrm{X}$ was capecitabine $1000 \mathrm{mg} \mathrm{m}^{-2}$ b.d. on days 1-14 only of a cycle repeated every 21 days.

Before each cycle, toxicity was scored with Common Terminology Criteria for Adverse Events version 3.0 (CTCAEv3). Detailed management of side effects was specified; briefly, grade one and worse effects were treated symptomatically; persisting grade two and worse toxicity at day 1 of the next treatment cycle incurred a 1 -week delay. Cytotoxic doses were reduced by $25 \%$ after two delays, or one delay of $\geqslant 2$ weeks. Compliance with capecitabine was assessed with patient diary cards and tablet returns.

At 6 weeks, doses could be escalated to $100 \%$ of standard doses provided that no grade two or worse non-haematological toxic effects had occurred and that the patient consented. After week 12, radiological response was assessed with Response Evaluation Criteria in Solid Tumours (RECIST v1.1) criteria; the clinician assessed whether there had been clinical deterioration in the patient and the CHA was repeated. Thereafter, patients without radiological or clinical evidence of deterioration could continue the same regimen for up to 12 further weeks (four further cycles). Please see Supplementary Appendix for full trial protocol.

Statistical analysis. The primary outcome measure to determine feasibility was the rate of recruitment achievable over 18 months in two UK cancer networks. For a national phase three trial planned as a non-inferiority trial, using a non-inferiority margin of a 1-month reduction in median PFS between any two of the three regimens, with $80 \%$ power at the one-sided $5 \%$ significance level, 720 patients would be needed. The Yorkshire and Humber cancer networks have a combined population of $3.5 \mathrm{M}$, representing $5.7 \%$ of the UK population, and hence making the assumption that 
recruitment locally would be twice that of elsewhere given 'local interest', accrual of over 45 patients in 18 months would suggest a national study could recruit 750 patients over 3 years. Additionally, data were collected for the number of patients at each participating network considered for or denied palliative chemotherapy for advanced GO cancer, and the proportion randomised into $321 \mathrm{GO}$.

Secondary outcomes sought to describe tolerability of the regimens and included: the incidence of CTCAEv3 grade $\geqslant$ three non-haematological toxicities at 6 weeks, the incidence of SAEs and dose delays/reductions, the ability/willingness to dose escalate to $100 \%$ at week 6 , patient acceptability scores, quality of life and nutritional and symptom changes.

Progression-free survival (PFS) and overall survival (OS) were also pre-specified as descriptors to enable informed sample size calculations for a subsequent phase three trial.

This novel design for a feasibility study embedded within it an OTU assessment, a patient-centred tool that was first used within the FOCUS2 trial that examined chemotherapy options in a frail and elderly colorectal cancer population. As a composite end point, it was found to be better able to discriminate between different regimens than more conventional end points such as PFS (Seymour et al, 2011). The OTU was scored at 12 weeks. Good OTU was defined as no clinical or radiological evidence of disease progression, and no major negative treatment effects in terms of toxicity or patient acceptability. Intermediate OTU signified either clinical deterioration but no negative treatment effect, or a significant negative treatment effect but no clinical deterioration. Poor OTU indicated both clinical deterioration and a major negative treatment effect, or death. The patient acceptability score was determined by the response to two questions, 'How much has your treatment interfered with daily activities?' and 'How worthwhile has your treatment been?' the options being not 'very much' or 'very much' and not 'not at all' or 'not at all'.

\section{RESULTS}

In total, over the 18-month study period, 313 patients with advanced GO cancer were discussed at participating multidisciplinary team meetings of which 115 (36\%) received standard treatment (EOX at full dose), 89 (28\%) patients less than standard treatment and $111(36 \%)$ no treatment. Of the patients receiving less than standard treatment, 55 patients were recruited to $321 \mathrm{GO}$ representing an accrual rate of three patients per month. For those patients who did not enter the study but received non-standard chemotherapy, the majority, 29 patients (85\%), received either three- or two-drug chemotherapy regimens (Figure 1). Median age was 75 years (range 50-87). Six (11\%) patients had a WHO performance status (PS) of $0,31(56 \%)$ had a PS of one and 18 (33\%) had a PS of two (Table 1). The main reasons stated by investigators for entry into $321 \mathrm{GO}$ were borderline performance status (40\%), general medical comorbidity (40\%) and advanced age (64\%; Table 2).

In addition, $44(80 \%)$ patients were still receiving treatment at 6 weeks and hence were eligible for dose escalation to standard doses. Of these, 10 (23\%) had a dose escalation, although none of these patients maintained this escalation in dose past cycle four. Then, $43(80 \%)$ patients stopped treatment before completing all 8 cycles of treatment. In addition, 10 (19\%) had a dose reduction either at cycle two or three because of toxicity. At the 6-week assessment, 22 patients (41\%) had experienced a grade three nonhaematologic or greater toxicity or serious adverse event, the most common toxicities at grade three or worse being lethargy and diarrhoea (Table 3).

Overall, median PFS was 4.4 months (Figure 2A). By arm, median PFS was 5.4, 5.6 and 3.0 months for patients receiving

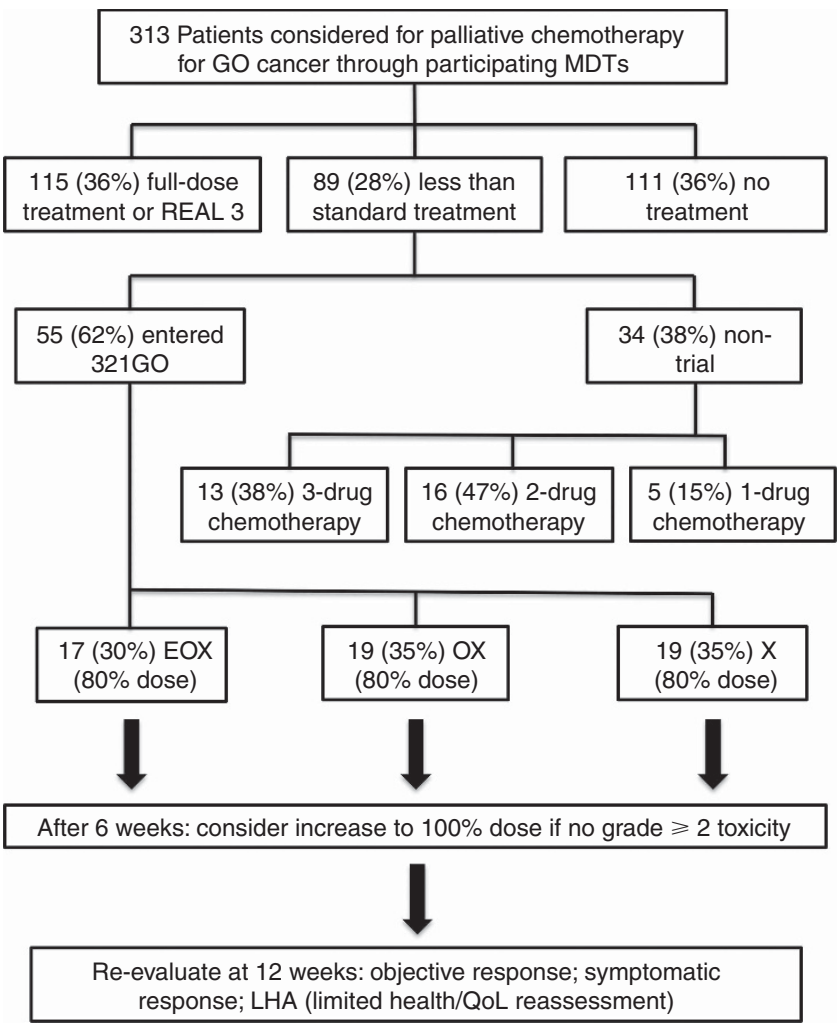

Figure 1. Trial flowchart and decision pathway for patients considered for palliative chemotherapy for advanced GO cancer.

\section{Table 1. Patient characteristics}

\begin{tabular}{|c|c|c|c|c|}
\hline & $\begin{array}{c}\text { EOX } \\
(n=17)\end{array}$ & $\begin{array}{c}\text { OX } \\
(n=19)\end{array}$ & $\begin{array}{c}X \\
(n=19)\end{array}$ & $\begin{array}{c}\text { Total } \\
(n=55)\end{array}$ \\
\hline \multicolumn{5}{|l|}{ Sex } \\
\hline Men & $13(76 \%)$ & $13(68 \%)$ & 15 (79\%) & 41 (75\%) \\
\hline Women & $4(24 \%)$ & $6(32 \%)$ & $4(21 \%)$ & $14(25 \%)$ \\
\hline
\end{tabular}

\section{Age (years)}

\begin{tabular}{|l|r|r|r|r|}
\hline Median & 74 & 77 & 75 & \multicolumn{1}{|c|}{75} \\
IQR & $70-77$ & $70-79$ & $70-78$ & $70-78$ \\
Range & $64-82$ & $50-85$ & $57-87$ & $50-87$ \\
\hline WHO performance status \\
\hline 0 & $0(0 \%)$ & $4(21 \%)$ & $2(11 \%)$ & $6(11 \%)$ \\
1 & $11(65 \%)$ & $10(53 \%)$ & $10(53 \%)$ & $31(56 \%)$ \\
2 & $6(35 \%)$ & $5(26 \%)$ & $7(37 \%)$ & $18(33 \%)$
\end{tabular}

\section{Primary tumour site}

\begin{tabular}{|c|c|c|c|c|}
\hline Oesophagus & $5(29 \%)$ & $11(58 \%)$ & $8(42 \%)$ & $24(44 \%)$ \\
\hline Gastroesophageal junction & 2 (12\%) & $1(5 \%)$ & $4(21 \%)$ & $9(16 \%)$ \\
\hline Gastric & 10 (59\%) & $5(26 \%)$ & 7 (37\%) & $22(40 \%)$ \\
\hline Unknown & $0(0 \%)$ & $1(5 \%)$ & $0(0 \%)$ & $1(2 \%)$ \\
\hline \multicolumn{5}{|l|}{ Metastases } \\
\hline Yes & $17(100 \%)$ & $17(89 \%)$ & $18(95 \%)$ & $52(95 \%)$ \\
\hline No & $0(0 \%)$ & $2(11 \%)$ & 1 (5\%) & $3(5 \%)$ \\
\hline \multicolumn{5}{|l|}{ Histology } \\
\hline Squamous cell carcinoma & $2(12 \%)$ & $3(16 \%)$ & $1(5 \%)$ & $6(11 \%)$ \\
\hline Adenocarcinoma & 15 (88\%) & $15(79 \%)$ & 18 (95\%) & $48(87 \%)$ \\
\hline Mixed squamous + adenocarcinoma & $0(0 \%)$ & $1(5 \%)$ & $0(0 \%)$ & $1(2 \%)$ \\
\hline
\end{tabular}

Abbreviations: $E O X=$ epirubicin, oxaliplatin and capecitabine; $I Q R=$ interquartile range; $\mathrm{OX}=$ oxaliplatin and capecitabine; $\mathrm{WHO}=$ World Health Organisation; $\mathrm{X}=$ capecitabine

EOX, OX and X, respectively (Figure 2B). Median overall survival was 7.1 months (Figure 2C). By arm, median OS was 8.1, 9.5 and 3.6 months for patients receiving EOX, OX and X, respectively (Figure 2D). At 12 weeks, the RECIST response rate for all patients 
Table 2. Reasons given by investigators for trial participation

\begin{tabular}{|c|c|c|c|c|}
\hline & $\begin{array}{c}\text { EOX } \\
(n=17)\end{array}$ & $\begin{array}{c}\text { OX } \\
(n=19)\end{array}$ & $\begin{array}{c}X \\
(n=19)\end{array}$ & $\begin{array}{c}\text { Total } \\
(n=55)\end{array}$ \\
\hline \multicolumn{5}{|c|}{ Borderline performance status } \\
\hline Yes & $8(47 \%)$ & $6(32 \%)$ & $8(42 \%)$ & $22(40 \%)$ \\
\hline No & $9(53 \%)$ & $13(68 \%)$ & $11(58 \%)$ & $33(60 \%)$ \\
\hline \multicolumn{5}{|c|}{ General medical comorbidity } \\
\hline Yes & $8(47 \%)$ & $7(37 \%)$ & $7(37 \%)$ & $22(40 \%)$ \\
\hline No & $9(53 \%)$ & 12 (63\%) & $12(63 \%)$ & $33(60 \%)$ \\
\hline \multicolumn{5}{|c|}{ Borderline renal or hepatic function } \\
\hline Yes & $3(18 \%)$ & $2(11 \%)$ & $1(5 \%)$ & $6(11 \%)$ \\
\hline No & $14(82 \%)$ & 17 (89\%) & $18(95 \%)$ & 49 (89\%) \\
\hline \multicolumn{5}{|c|}{ Advanced age } \\
\hline Yes & $9(53 \%)$ & $13(68 \%)$ & $13(68 \%)$ & $35(64 \%)$ \\
\hline No & $8(47 \%)$ & 6 (32\%) & 6 (32\%) & $20(36 \%)$ \\
\hline \multicolumn{5}{|c|}{ Other reason } \\
\hline Yes & $1(6 \%)$ & $0(0 \%)$ & $1(5 \%)$ & $2(4 \%)$ \\
\hline No & $16(94 \%)$ & 19 (100\%) & $18(95 \%)$ & $53(96 \%)$ \\
\hline \multicolumn{5}{|c|}{$\begin{array}{l}\text { Abbreviations: EOX = epirubicin, oxaliplatin and capecitabine; } O X=0 x a l i p l a t i n \text { and } \\
\text { capecitabine; } X=\text { capecitabine. Other reasons reported: 'not fit for full-dose chemotherapy' } \\
(X) ; \text { 'clinician decision' (EOX). }\end{array}$} \\
\hline
\end{tabular}

was (complete response + partial response) $30 \%$ and there was evidence of disease control (complete response + partial response + stable disease) in $54 \%$ of patients (Table 4 ). At 12 weeks, the mean global QoL score, adjusted for baseline values, was 67.8, 70.3 and 64.8 for patients receiving EOX, OX and X. Mean fatigue score was 31.7, 25.6 and 42.6, respectively (Table 4).

Although not a pre-determined end point in this study, the feasibility of using OTU as an outcome measure was assessed in view of the proposed use of OTU as an outcome measure in a phase three trial for this population. The percentage of patients with a good OTU was $18 \%, 32 \%$ and $17 \%$ with EOX, OX and X, and was $19 \%$ overall. The OTU was prognostic for OS in patients alive at week 12 (logrank test for trend $P=0.0001$ ) and PFS in patients alive and progression free at week 12 (logrank test for trend $P=0.0001$ ). Of note, radiological response (RECIST) was less prognostic for OS (logrank test for trend $P=0.40$ ).

\section{DISCUSSION}

There is a growing need for RCTs targeted at the elderly and frail cancer population and this prompts the evaluation of new feasibility and late phase trial designs that fit the specific needs of this group. Feasibility studies are usually designed to determine the practicality of randomising the population in question, the sample size needed for the main study and sometimes to help decide the outcome measure. Such studies may not be reported in the peer-reviewed literature and there is a need for an ongoing discussion as to best practice with regard to design (Arain et al, 2010) The $321 \mathrm{GO}$ incorporated novel elements to determine late phase feasibility. Firstly, besides making an assessment of recruitment rate, data to determine the proportional recruitment from all patients considered for chemotherapy were collected. Secondly, data were collected with regard to global patient benefit. Given that survival benefits may be more limited in this vulnerable group, we believe an early assessment of QoL as an outcome measure is important to aid phase three design.

This trial demonstrates that elderly and frail patients with advanced GO cancer can be randomised into a clinical trial and undergo complex assessment of clinical benefit. The registry study showed that almost half of those patients who received
Table 3. Tolerability

\begin{tabular}{c|c|c|c}
$\underset{(n=17)}{\text { EOX }}$ & $\underset{(n=19)}{\text { OX }}$ & $X(n=19)$ & $\begin{array}{c}\text { Total } \\
(n=55)\end{array}$ \\
\hline
\end{tabular}

Grade $3+$ non-haematological toxicities (at 6-week assessment)

\begin{tabular}{|l|l|l|l|l|}
\hline Any toxicity or SAR & $8(47 \%)$ & $7(37 \%)$ & $7(39 \%)$ & $22(41 \%)$ \\
\hline
\end{tabular}

\begin{tabular}{l|l|l|l|l|} 
Nausea & $2(12 \%)$ & $0(0 \%)$ & $0(0 \%)$ & $2(4 \%)$ \\
\hline
\end{tabular}

\begin{tabular}{l|l|l|l|l} 
Vomiting & $1(6 \%)$ & $1(5 \%)$ & $0(0 \%)$ & $2(4 \%)$
\end{tabular}

\begin{tabular}{l|l|l|l|l} 
Anorexia & $1(6 \%)$ & $0(0 \%)$ & $0(0 \%)$ & $1(2 \%)$
\end{tabular}

\begin{tabular}{l|l|l|l|l} 
Stomatitis & $0(0 \%)$ & $0(0 \%)$ & $1(6 \%)$ & $1(2 \%)$
\end{tabular}

\begin{tabular}{l|l|l|l|l} 
Diarrhoea & $2(12 \%)$ & $0(0 \%)$ & $2(11 \%)$ & $4(7 \%)$
\end{tabular}

\begin{tabular}{l|l|l|l|l}
\hline Lethargy & $4(24 \%)$ & $2(11 \%)$ & $1(6 \%)$ & $7(13 \%)$
\end{tabular}

\begin{tabular}{l|l|l|l|l} 
Peripheral neuropathy & $0(0 \%)$ & $1(5 \%)$ & $0(0 \%)$ & $1(2 \%)$
\end{tabular}

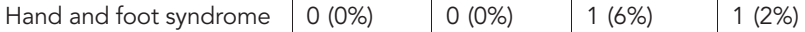

\begin{tabular}{|c|c|}
\hline Other & $404^{\circ}$ \\
\hline
\end{tabular}

Treatment delay (at cycles 2 or 3 )

\begin{tabular}{|l|l|l|l|l|}
\hline $\begin{array}{l}\text { Yes } \\
\text { No }\end{array}$ & $\begin{array}{l}5(29 \%) \\
12(71 \%)\end{array}$ & $\begin{array}{l}2(11 \%) \\
17(89 \%)\end{array}$ & $\begin{array}{l}2(11 \%) \\
16(89 \%)\end{array}$ & $\begin{array}{l}9(17 \%) \\
45(83 \%)\end{array}$ \\
\hline Dose reduction (at cycles 2 or 3$)$ \\
\hline Yes & $4(24 \%)$ & $3(16 \%)$ & $3(17 \%)$ & $10(19 \%)$ \\
No & $13(76 \%)$ & $16(84 \%)$ & $15(83 \%)$ & $44(81 \%)$ \\
\hline Treatment stopped at any time during trial \\
\hline Yes & $13(76 \%)$ & $16(84 \%)$ & $14(78 \%)$ & $43(80 \%)$ \\
No & $4(24 \%)$ & $3(16 \%)$ & $4(22 \%)$ & $11(20 \%)$ \\
\hline Dose escalation (at 6-week assessment) & $3(16 \%)$ & $5(28 \%)$ & $10(19 \%)$ \\
\hline Yes & $2(12 \%)$ & $16(72 \%)$ & $44(81 \%)$ \\
No & $15(88 \%)$ & $16(84 \%)$ & $13(72 \%)$
\end{tabular}

Abbreviations: EOX=epirubicin, oxaliplatin and capecitabine; $O X=$ oxaliplatin and capecitabine; $\mathrm{SAR}=$ serious adverse reaction; $\mathrm{X}=$ capecitabine.

chemotherapy received less than full-dose treatment and hence confirms that this is a substantial patient group, supporting the need for an evidence base. The population recruited to $321 \mathrm{GO}$ (median age of 75 years and PS2 in 33\% of cases) had very different baseline characteristics compared with the recent REAL2 and REAL3 trials (median age, 61-65 (dependent on arm) years and 62-63 years; PS2 $8.5-12.4 \%$ and $5-6 \%$ of patients, respectively) (Cunningham et al, 2008; Waddell et al, 2013). The recruitment rate of three patients per month within the Yorkshire Cancer Network is consistent with the number needed to appropriately power a national phase three trial.

The use of OTU as a more patient-centred approach in assessing benefit from cancer therapy was first explored in the FOCUS2 trial in which OTU demonstrated unequivocal benefit from oxaliplatin chemotherapy in elderly and frail patients with advanced colorectal cancer when other more standard endpoints were divergent (Seymour et al, 2011). In 321GO, OTU was found to be useful in comparing regimens to take through to a phase three trial and indeed was more prognostic for OS than the more standard end point, radiological response. There was good compliance with regard to completing the baseline $\mathrm{CHA}$ and hence this may have potential as a tool to discriminate between patients who are more likely to benefit from chemotherapy and those not (Table 5).

In reporting the results of $321 \mathrm{GO}$ we have deliberately avoided reporting some of the standard outcomes seen in standard phase II trials. Specifically, we have omitted a full breakdown of low-grade toxicities, instead relying on tolerability metrics and assessments of quality of life and functional outcomes as better reflecting the impact on patients.

In the FOCUS2 trial, $37 \%$ of patients had a dose escalation to $100 \%$ of standard doses, although only $14 \%$ (of all patients who had started treatment) sustained this higher dose to 12 weeks. Within $321 \mathrm{GO}$, none of the patients who had a dose escalation after two cycles maintained this past cycle four, and hence this does not seem to be a sensible strategy in frail and elderly patients with advanced GO cancer. 

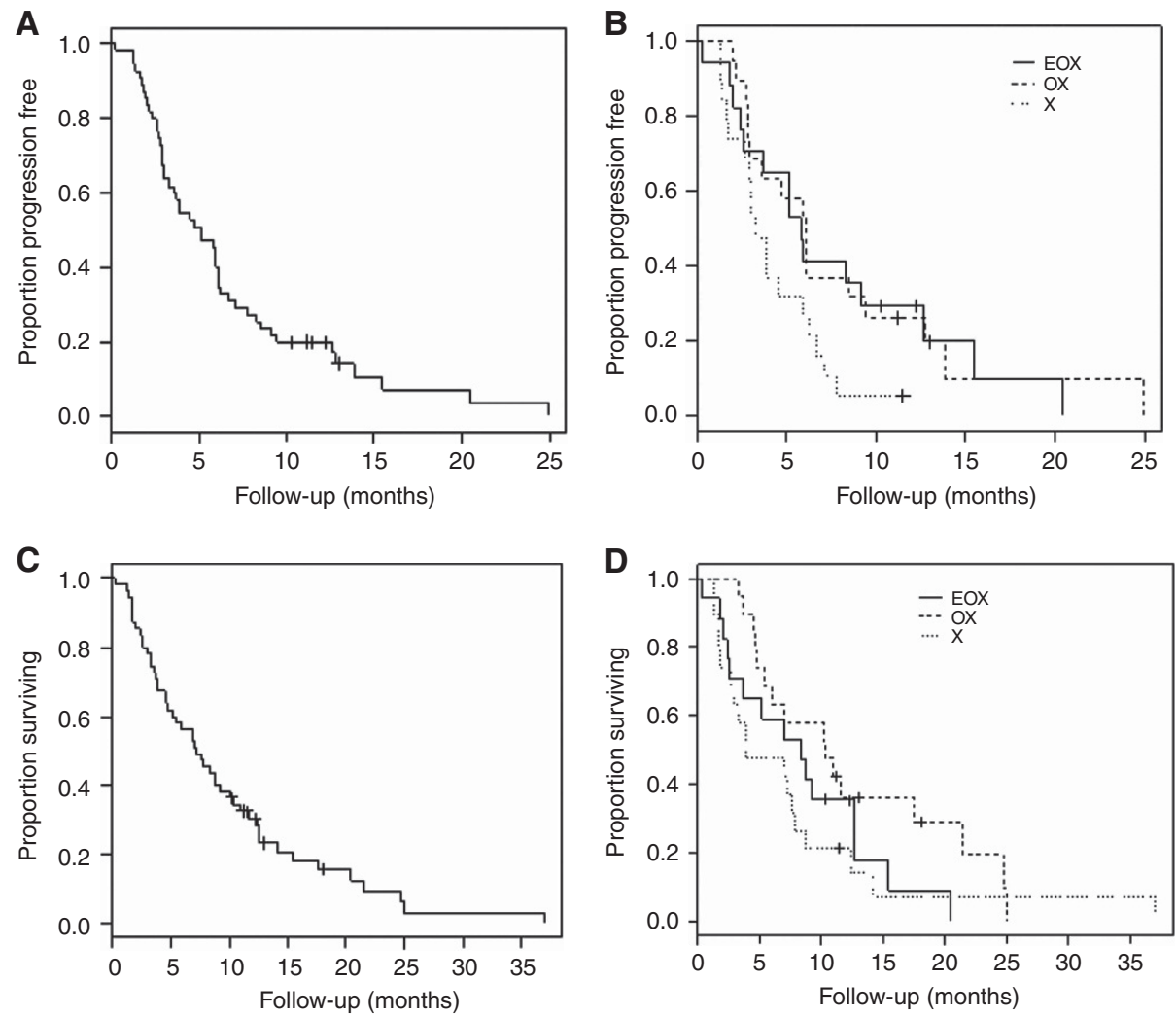

Figure 2. Survival curves. (A) Kaplan-Meier estimate of progression-free survival for all patients in the study, (B) Kaplan-Meier estimates of progression-free survival for each arm, (C) Kaplan-Meier estimate of overall survival for all patients in the study and (D) Kaplan-Meier estimate of overall survival for each arm.

\begin{tabular}{|c|c|c|c|c|}
\hline & $\operatorname{EOX}(n=17)$ & OX $(n=19)$ & $X(n=19)$ & Total $(n=55)$ \\
\hline Median PFS (months; 95\% Cl) & $5.4(2.3-11.7)$ & $5.6(2.7-8.7)$ & $3.0(2.4-4.1)$ & $4.4(2.8-5.6)$ \\
\hline Median OS (months; 95\% Cl) & $8.1(2.3-11.7)$ & 9.5 (5.0-NR) & $3.6(2.4-8.1)$ & $7.1(4.3-10.1)$ \\
\hline $\begin{array}{l}\text { RECIST response at week } 12 \\
\text { Response rate CR + PR } \\
\text { Disease control CR + PR + SD }\end{array}$ & $\begin{array}{c}5(29 \%) \\
10(59 \%)\end{array}$ & $\begin{array}{c}9(47 \%) \\
11(58 \%)\end{array}$ & $\begin{array}{l}2(11 \%) \\
8(44 \%)\end{array}$ & $\begin{array}{l}16(30 \%) \\
29(54 \%)\end{array}$ \\
\hline $\begin{array}{l}\text { OTU score at week } 12 \\
\text { Good } \\
\text { Intermediate } \\
\text { Poor } \\
\text { Missing }\end{array}$ & $\begin{array}{l}3(18 \%) \\
4(24 \%) \\
8(47 \%) \\
2(12 \%)\end{array}$ & $\begin{array}{l}6(32 \%) \\
4(21 \%) \\
6(32 \%) \\
3(16 \%)\end{array}$ & $\begin{array}{c}1(6 \%) \\
4(22 \%) \\
10(56 \%) \\
3(17 \%)\end{array}$ & $\begin{array}{c}10(19 \%) \\
12(22 \%) \\
24(44 \%) \\
8(15 \%)\end{array}$ \\
\hline $\begin{array}{l}\text { Patient acceptability scores } \\
\text { Category } \mathrm{A} \gamma \\
\text { Category } \mathrm{B} \eta \\
\text { Died before assessment } \\
\text { Missing }\end{array}$ & $\begin{array}{l}3(18 \%) \\
7(41 \%) \\
5(29 \%) \\
2(12 \%)\end{array}$ & $\begin{array}{c}6(32 \%) \\
9(47 \%) \\
1(5 \%) \\
3(16 \%)\end{array}$ & $\begin{array}{l}3(17 \%) \\
6(33 \%) \\
6(33 \%) \\
3(17 \%)\end{array}$ & $\begin{array}{c}12(22 \%) \\
22(41 \%) \\
12(22 \%) \\
8(15 \%)\end{array}$ \\
\hline $\begin{array}{l}\text { QLQ-C30 scores at week } 12 \\
\text { Mean global QoL score at } 12 \text { weeks }^{\text {a }} \\
\text { Mean fatigue score at } 12 \text { weeks }\end{array}$ & $\begin{array}{l}67.8(\mathrm{Cl} 54.5-81.2) \\
31.7(\mathrm{Cl} 18.4-45.1)\end{array}$ & $\begin{array}{l}70.3(\mathrm{Cl} 58.3-82.3) \\
25.6(\mathrm{Cl} 14.3-37.0)\end{array}$ & $\begin{array}{l}64.8 \text { (Cl 51.5-78.2) } \\
42.6 \text { (Cl 29.3-55.8) }\end{array}$ & $\begin{array}{l}67.0(\mathrm{Cl} 60.1-73.8) \\
32.9(\mathrm{Cl} 25.9-40.0)\end{array}$ \\
\hline $\begin{array}{l}\text { Mini-nutritional assessment } \\
\text { Mean global MNA score at week } 12^{\text {a }}\end{array}$ & b & 24.2 (Cl 22.3-26.2) & $25.8(\mathrm{Cl} 21.0-30.6)$ & $24.2(\mathrm{Cl} 22.5-25.9)$ \\
\hline $\begin{array}{l}\text { Nottingham ADL at week } 12 \\
\text { Mean global NADL score at } 12 \text { weeks }^{\text {a }}\end{array}$ & 13.4 (Cl 11.4-15.3) & 14.8 (Cl 13.0-16.5) & $14.3(\mathrm{Cl} 12.4-16.3)$ & 14.2 (Cl 13.2-15.2) \\
\hline $\begin{array}{l}\text { Physical tests at week } 12 \\
\text { Mean weight at } 12 \text { weeks }{ }^{\text {a }} \\
\text { Mean arm circumference at } 12 \text { weeks }^{\text {a }}\end{array}$ & $\begin{array}{l}65.8(\mathrm{Cl} 62.1-69.4) \\
24.5(\mathrm{Cl} 23.1-26.0)\end{array}$ & $\begin{array}{l}69.3(\mathrm{Cl} 66.7-71.9) \\
25.5(\mathrm{Cl} 24.2-26.8)\end{array}$ & $\begin{array}{l}67.4(\mathrm{Cl} 64.5-70.3) \\
23.3(\mathrm{Cl} 21.8-24.8)\end{array}$ & $\begin{array}{l}67.6(\mathrm{Cl} 65.9-69.3) \\
24.4(\mathrm{Cl} 23.6-25.2)\end{array}$ \\
\hline \multicolumn{5}{|c|}{ 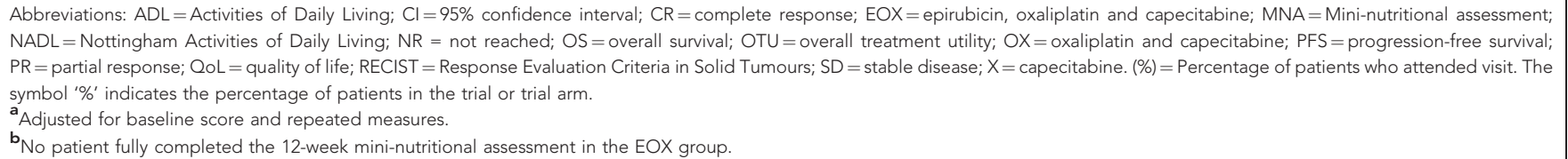 } \\
\hline
\end{tabular}


Table 5. Data compliance (\% indicates percentage of patients who attended visit)

\begin{tabular}{l|l|c|c|c|}
\hline & $\begin{array}{c}\text { EOX } \\
(\mathbf{n = 1 7 )}\end{array}$ & $\begin{array}{c}\text { OX } \\
(\mathbf{n = 1 9 )}\end{array}$ & $\begin{array}{c}\text { X } \\
(\mathbf{n = 1 9 )}\end{array}$ & $\begin{array}{c}\text { Total } \\
(\mathbf{n = 5 5 )}\end{array}$ \\
\hline QoL questionnaire \\
\hline Baseline CHA & $16(94 \%)$ & $19(100 \%)$ & $19(100 \%)$ & $54(98 \%)$ \\
6-Week TA & $8(73 \%)$ & $15(79 \%)$ & $12(67 \%)$ & $35(67 \%)$ \\
12-Week LHA & $8(73 \%)$ & $12(71 \%)$ & $9(90 \%)$ & $29(76 \%)$ \\
24-Week LHA & $8(100 \%)$ & $8(73 \%)$ & $4(50 \%)$ & $20(74 \%)$ \\
\hline Abbreviations: CHA =Comprehensive Health Assessment; EOX=epirubicin, oxaliplatin \\
and capecitabine; LHA = Limited Health Assessment; OX=oxaliplatin and capecitabine; \\
QoL=quality of life; SAR=serious adverse reaction; TA=Toxicity Assessment; \\
X=capecitabine.
\end{tabular}

A median PFS of 4.4 months and OS of 7.1 months was less than comparator studies using standard doses of chemotherapy consistent with this frailer population (Cunningham et al, 2010). However, for a cohort of patients, overall QoL improved with treatment. The question remains open as to whether palliative chemotherapy for this group of patients is of benefit and if so which chemotherapy regimens are most likely to provide clinical benefit. Given the poorer PFS, OS and OTU scores for EOX vs OX, this study questions the value of anthracyclines as part of combination chemotherapy for advanced gastroesophageal cancer. Recent evidence in both the adjuvant and advanced setting has also suggested that anthracyclines may add little in the treatment of gastroesophageal cancer (Guimbaud et al, 2014; Alderson et al, 2015).

A phase three trial has been demonstrated as feasible and is now required to definitively provide an evidence base to guide the treatment of patients who are frail or elderly with advanced gastric and oesophageal cancer. Although the results of $321 \mathrm{GO}$ could be interpreted as favouring a doublet regimen over single agent or triplet chemotherapy, it remains to be determined whether the OX regimen used represents an overdosing or underdosing for the specific patients groups included in the trial. In an attempt to answer this question, based on the success of $321 \mathrm{GO}$, the phase three trial GO2 recently commenced recruitment across 56 sites in the United Kingdom to determine the optimal dose intensity of $\mathrm{OX}$ in this patient population. Further information about GO2 is available via weblink http:// www.cancerresearchuk.org/about-cancer/find-a-clinical-trial/a-triallooking-at-chemotherapy-for-people-with-advanced-cancer-of-thestomach-or-food-pipe-go2. We also recommend that further research beyond the $321 \mathrm{GO}$ and GO2 programme should consider alternative agents such as S1 or targeted therapies as they emerge from research pipelines.

\section{ACKNOWLEDGEMENTS}

This trial was run within the National Health Service and supported by the National Institute of Health Research (NIHR) National Cancer Research Network. We thank the 55 participating patients, clinicians, research nurses and other support staff in the participating centres. This work was supported by a Feasibility Study Project Grant from Cancer Research UK (CRUK/08/033) and an unconditional grant from Roche.

\section{CONFLICT OF INTEREST}

Roche provided an unconditional grant but had no influence over the design or publication of this study. MTS has received travel, accommodation and departmental research funding (unconnected with 321GO) from Roche. PSH was formerly employed by the University of Leeds on a research grant from Roche as a trial administrator for an unconnected project. SRL has received travel and accommodation funding from Roche (unconnected with 321GO). MTS, HM, MJ, and HH are employed by the University of Leeds, the study sponsor.

\section{REFERENCES}

Aaronson NK, Ahmedzai S, Bergman B, Bullinger M, Cull A, Duez NJ, Filiberti A, Flechtner H, Fleishman SB, de Haes JCJM, Kaasa S, Klee M, Osoba D, Razavi D, Rofe PB, Schraub S, Sneeuw K, Sullivan M, Takeda F (1993) The European Organization for Research and Treatment of Cancer QLQ-C30: a quality-of-life instrument for use in international clinical trials in oncology. J Natl Cancer Inst 85: 365-376.

Alderson D, Langley RE, Nankivell MG, Blazeby JM, Griffin M, Crellin A, Grabsch HI, Okines AFC, Goldstein C, Falk S, Thompson J, Krysztopik R, Coxon FY, Pritchard S, Langer R, Stenning SP, Cunningham D (2015) Neoadjuvant chemotherapy for resectable oesophageal and junctional adenocarcinoma: results from the UK Medical Research Council randomised OEO5 trial (ISRCTN 01852072). J Clin Oncol 33: (suppl; abstr 4002).

Arain M, Campbell MJ, Cooper CL, Lancaster GA (2010) What is a pilot or feasibility study? A review of current practice and editorial policy. BMC Med Res Methodol 10: 67.

Charlson ME, Pompei P, Ales KL, MacKenzie CR (1987) A new method of classifying prognostic comorbidity in longitudinal studies: development and validation. J Chronic Dis 40: 373-383.

Cunningham D, Okines AF, Ashley S (2010) Capecitabine and oxaliplatin for advanced esophagogastric cancer. $N$ Engl J Med 362: 858-859.

Cunningham D, Starling N, Rao S, Iveson T, Nicolson M, Coxon F, Middleton G, Daniel F, Oates J, Norman AR (2008) Capecitabine and oxaliplatin for advanced esophagogastric cancer. $N$ Engl J Med 358: $36-46$.

Guigoz Y, Vellas BJ (1997) Malnutrition in the elderly: the Mini Nutritional Assessment (MNA). Ther Umsch 54: 345-350.

Guimbaud R, Louvet C, Ries P, Ychou M, Maillard E, Andre T, Gornet JM, Aparicio T, Nguyen S, Azzedine A, Etienne PL, Boucher E, Rebischung C, Hammel P, Rougier P, Bedenne L, Bouche O (2014) Prospective, randomized, multicenter, phase III study of fluorouracil, leucovorin, and irinotecan versus epirubicin, cisplatin, and capecitabine in advanced gastric adenocarcinoma: a French intergroup (Federation Francophone de Cancerologie Digestive, Federation Nationale des Centres de Lutte Contre le Cancer, and Groupe Cooperateur Multidisciplinaire en Oncologie) study. J Clin Oncol 32: 3520-3526.

Kind P (1996) The EuroQoL instrument: an index of health-related quality of life. In Quality of Life and Pharmacoeconomics in Clinical Trials, Spiker B (ed), Lippincott-Raven: Philadelphia, pp 191-201.

Lagergren P, Fayers P, Conroy T, Stein HJ, Sezer O, Hardwick R, Hammerlid E, Bottomley A, Van Cutsem E, Blazeby JM, European Organisation for Research Treatment of Cancer Gastrointestinal and Quality of Life Groups (2007) Clinical and psychometric validation of a questionnaire module, the EORTC QLQ-OG25, to assess health-related quality of life in patients with cancer of the oesophagus, the oesophagogastric junction and the stomach. Eur J Cancer 43: 2066-2073.

Nouri FM, Lincoln NB (1987) An extended activities of daily living scale for stroke patients. Clin Rehabil 1: 301-305.

Popescu RA, Norman A, Ross PJ, Parikh B, Cunningham D (1999) Adjuvant or palliative chemotherapy for colorectal cancer in patients 70 years or older. J Clin Oncol 17: 2412-2418.

Sargent DJ, Goldberg RM, Jacobson SD, Macdonald JS, Labianca R, Haller DG, Shepherd LE, Seitz JF, Francini G (2001) A pooled analysis of adjuvant chemotherapy for resected colon cancer in elderly patients. $N$ Engl J Med 345: 1091-1097.

Seymour MT, Thompson LC, Wasan HS, Middleton G, Brewster AE, Shepherd SF, O'Mahony MS, Maughan TS, Parmar M, Langley RE, FOCUS2 Investigators, National Cancer Research Institute Colorectal Cancer Clinical Studies Group (2011) Chemotherapy options in elderly and frail patients with metastatic colorectal cancer (MRC FOCUS2): an open-label, randomised factorial trial. Lancet 377: 1749-1759. 
Shitara K, Muro K, Matsuo K, Ura T, Takahari D, Yokota T, Sawaki A, Kawai H, Ito S, Munakata M, Sakata Y (2009) Chemotherapy for patients with advanced gastric cancer with performance status 2. Gastrointest Cancer Res 3: 220-224.

Simonsick EM, Gardner AW, Poehlman ET (2000) Assessment of physical function and exercise tolerance in older adults: reproducibility and comparability of five measures. Aging (Milano) 12: 274-280.

Stein BN, Petrelli NJ, Douglass HO, Driscoll DL, Arcangeli G, Meropol NJ (1995) Age and sex are independent predictors of 5-fluorouracil toxicity. Analysis of a large scale phase III trial. Cancer 75: 11-17.

Trumper M, Ross PJ, Cunningham D, Norman AR, Hawkins R, Seymour M, Harper P, Iveson T, Nicolson M, Hickish T (2006) Efficacy and tolerability of chemotherapy in elderly patients with advanced oesophago-gastric cancer: a pooled analysis of three clinical trials. Eur J Cancer 42: 827-834.
Waddell T, Chau I, Cunningham D, Gonzalez D, Okines AF, Okines C, Wotherspoon A, Saffery C, Middleton G, Wadsley J, Ferry D, Mansoor W, Crosby T, Coxon F, Smith D, Waters J, Iveson T, Falk S, Slater S, Peckitt C, Barbachano Y (2013) Epirubicin, oxaliplatin, and capecitabine with or without panitumumab for patients with previously untreated advanced oesophagogastric cancer (REAL3): a randomised, open-label phase 3 trial. Lancet Oncol 14: 481-489.

This work is published under the standard license to publish agreement. After 12 months the work will become freely available and the license terms will switch to a Creative Commons AttributionNonCommercial-Share Alike 4.0 Unported License.

Supplementary Information accompanies this paper on British Journal of Cancer website (http://www.nature.com/bjc) 